\title{
Child health Care delivery system in Rewa District: A critical analysis
}

\author{
Gupta $\mathbf{R}^{1}$, Gupta $\mathbf{J}^{2}$ \\ ${ }^{1}$ Dr Rajesh Gupta, Assistant Professor, Department of Pediatrics, R D Gardi Medical College, Ujjain, MP, India, \\ ${ }^{2}$ Dr Jyoti Gupta, Department of Microbiology, Chirayu Medical college, Bhaisakhedi, Bhopal, M.P, India
}

Address for correspondence: Dr Rajesh Gupta, Email: drrajesh93@ gmail.com

\begin{abstract}
Background : In developing countries like India, a very high proportion of the population especially in rural areas of Madhya Pradesh does not have ready access to neonatal and child health care services. There is an urgent need for removal of obstacles to pediatric health to improve health indicators. Aims \& Objectives: To assess the infrastructure and quality of child health care delivery system in Rewa district of Madhya Pradesh. Material \& Method: A crosssectional observation study carried out at tertiary care hospital. 84 Auxiliary nurse midwives (ANMs), 16 Medical officers posted at primary health centres (PHCs) and 10 medical officers in-charge of Community health centres (CHCs) were interviewed through a predesigned questionnaire over a period of one year to assess neonatal and child health care services at sub centre, PHCs and CHCs respectively. Results: 91.66\% subcentres had male workers and $90.4 \%$ had ANMs. $53.5 \%$ subcentres are covering 5-10 villages and $20.2 \%$ were covering even more than 10 villages. $42.9 \%$ of studied subcentres did not have their buildings. 31.2\% of studied PHCs did not have doctor. 81.2\% PHCs are not having staff nurses, $43.7 \%$ of studied PHCs were not having their own buildings. Marked lack of specialists in CHCs was found affecting newborn care. Conclusion: Improvement in infrastructure and specialist facilities is needed to improve neonatal and child health care services as well as health indicators in Rewa district.
\end{abstract}

Keywords: Child Health, Health Care Delivery System, Infant mortality Rate, Neonatal Care

\section{Introduction}

Rewa district is situated in the eastern part of Madhya Pradesh province of India. Rewa is basically a plateau comprised of dissected hills, ravines plain, plateau, scrap, water fall and alluvial plain with $83.76 \%$ rural area [1]. Difficult geographical terrain affects health care facilities. The infant mortality rate (IMR) in Madhya Pradesh is the third highest among the states of India [2]. The infant mortality in NFHS-3 is estimated at 70 deaths before the age of one year per 1,000 live births. The under-five mortality rate, at 94 deaths per 1,000 live births, is the second highest in the country [2]. Health indicators discrepancies have also been noticed among different parts of Madhya Pradesh. According to Annual Health Survey (2010-11) IMR, Under 5 mortality rate (U5MR) and Neonatal Mortality Rate (NMR) of Madhya Pradesh is 67, 89, 44 per 1000 live births respectively and for Rewa district these indicators are 73,97 and 51 respectively [3].

Manuscript received: $25^{\text {th }}$ May 2015

Reviewed: $16^{\text {th }}$ June 2015

Author Corrected; $29^{\text {th }}$ June 2015

Accepted for Publication: $2^{\text {nd }}$ July 2015
Though improvement in health indicators is seen in Sample Registration Survey (SRS) as IMR of Madhya Pradesh is 54 (India 40/1000 live births) but it is still far behind the national figures [4]. Scarce health care facilities are pointed out in various surveys for lagging behind of Empowered action group state like Madhya Pradesh. Only $55.5 \%$ sub centre found to have their own building and only $55.6 \%$ villages were within the $10 \mathrm{Km}$ range of PHCs in the state [4]. Similarly manpower deficits have also been noticed at every level in the same survey [4]. District level data related to child health care delivery services is not readily available in the state of Madhya Pradesh. This study is carried out to identify health system related issues behind various child health indicators in Rewa district of Madhya Pradesh.

\section{Material \& Method}

This cross-sectional observation study was conducted at Department of Pediatrics, Gandhi Memorial Hospital associated with S.S. Medical College Rewa, during May 2007 to April 2008. Assessment of neonatal and 
child health care delivery system was done through interview of service providers i.e. 84 ANMs for subcentre level, 16 medical officers for PHC level and 10 medical officer-in-charge for $\mathrm{CHC}$ level. Random selection of health centres was done keeping in mind to include both remote and urban areas. Data was collected over a predesigned questionnaire. The data so obtained have been scrutinized and statistical analysis applied where needed to arrive at scientific, reasonable conclusion. The study was approved by institutional ethics committee and study subjects were informed about this study and their consents were obtained.

\section{Results}

Subcentre Level: $64.2 \%(n=54)$ subcentres were covering 5000-10000 population. Area of 25\% studied subcentres was hilly and forest area and $40 \%$ of those could be approached only by walking or cycle. In present study $91.66 \%$ subcentres were manned with MPWs and 90.4\% with ANMs. 53.5\% subcentres were covering 5-10 villages ( $\mathrm{n}=45)$ and $20.2 \%$ $(n=17)$ were covering even more than 10 villages. $42.9 \%(n=36)$ of studied subcentres did not have subcentre buildings. ANMs admitted that they are doing vaccination regularly on every Tuesday at their expected place but no other pediatric checkup / advice is being given.

At PHC Level: 6 PHCs were designated as BEmONC (Basic emergency maternal obstetric and neonatal care) centres. $31.5 \%(\mathrm{n}=5)$ PHCs were situated more than $50 \mathrm{~km}$ from Rewa headquarter. About one third of studied PHCs did not have doctors, $43.7 \%(\mathrm{n}=7)$ PHCs were having one doctor and rest 25\% had two doctors (Table 1). 81.2\% ( $\mathrm{n}=13)$ PHCs were not having staff nurses (Table 2), 43.7\% $(n=7)$ of studied PHCs were not having their own buildings. 56.3\% ( $\mathrm{n}=9$ ) studied PHCs had their average OPD attendance per month between 250-500 out of which 60-70\% patients were in pediatric age group. $56.2 \%(n=9)$ primary health centres were not conducting deliveries due to lack of staff or other facilities. Only two PHC staff was trained in newborn resuscitation. Vaccination was not practiced at $75 \%$ PHC buildings. Three PHCs were using Janani Express for referral of critical patients. Oxygen cylinders were being used at only two PHCs i.e. Baikunthpur and Lalgaon. Peripheral smears for malaria parasites were being prepared at all PHCs and medicines were being given accordingly.

Table 1: Distribution of PHCs according to available doctors

\begin{tabular}{|c|c|c|}
\hline S. No. & No. of Doctors & No. of PHCs \\
\hline 1 & Nil & $5(31.2 \%)$ \\
\hline 2 & 1 & $7(43.7 \%)$ \\
\hline 3 & 2 & $4(25 \%)$ \\
\hline
\end{tabular}

Table 2: Distribution of PHCs according to non-availability of medical/paramedical staff

\begin{tabular}{|c|c|c|}
\hline S. No. & Staff Designation & No. of PHCs \\
\hline 1 & Staff Nurses & $13(81.2 \%)$ \\
\hline 2 & Pharmacist/Compounder & $7(43.7 \%)$ \\
\hline 3 & Ward Boy & $2(12.5 \%)$ \\
\hline 4 & Sweeper & $9(56.2 \%)$ \\
\hline 5 & ANM & $4(25 \%)$ \\
\hline 6 & LHV & $2(12.5 \%)$ \\
\hline 7 & Dresser & $10(62.5 \%)$ \\
\hline
\end{tabular}

Table 3: Status of available doctor / specialist

\begin{tabular}{|c|c|c|}
\hline S. No. & Doctors & Number \\
\hline 1 & Gynecologist/ Female Doctor & 7 \\
\hline 2 & Medicine & 3 \\
\hline 3 & Pediatrician & 0 \\
\hline 4 & Anesthesia & 0 \\
\hline 5 & Surgery & \multicolumn{2}{|c|}{} \\
\hline
\end{tabular}




\begin{tabular}{|l|l|l|}
\hline 6 & Other specialist/MBBS & 22 \\
\hline
\end{tabular}

Table 4: Distribution of CHCs according to deliveries occurring per month

\begin{tabular}{|c|c|c|}
\hline S. No. & $\begin{array}{c}\text { Deliveries Criteria } \\
\text { (Average/Month) }\end{array}$ & No. of CHC \\
\hline 1 & $<100$ & $3(30 \%)$ \\
\hline 2 & $100-200$ & $4(40 \%)$ \\
\hline 3 & $>200$ & $3(30 \%)$ \\
\hline
\end{tabular}

At CHC Level: Five CHCs were designated as CEmONC (Comprehensive emergency maternal obstetric and neonatal care) centre and rest five were BEmONC. $80 \%(\mathrm{n}=8)$ CHCs were established covering population more than 2 lacs. $50 \%$ $\mathrm{CHCs}$ were situated more than $50 \mathrm{~km}$ from Rewa city. Total three pediatricians were working in studied $\mathrm{CHCs}$. $60 \%$ CHCs were providing indoor facility to their pediatric patients (Table 3). All CHCs were providing services for institutional deliveries (Table 4) but only three CHCs i.e. Hanumana, Sirmour and Jawa were using their neonatal care equipments. Only one CHC staff i.e. Hanumana was trained in newborn care. Caesarian sections were not done at any CHC. Oxygen delivery system and emergency light system was available at $90 \%$ CHCs.

\section{Discussion}

Health services should be organized to meet the needs of entire populations and not merely selected groups. Health services should cover the full range of preventive, curative and rehabilitation services. Health services are now seen as part of the basic social services of a country [5]. In present study, 64.2\% subcentres were covering 5000- 10000 population though the recommended population under each subcentre is 5000 for plain and 3000 for hilly areas [6]. Though 75\% subcentres of study cohort were in plain areas but lack of transportation modes and poor roads were the frequent complaints among study groups.

Area of $25 \%$ studied subcentres was hilly and forest area and $40 \%$ of those could be approached only by walking or cycle. In some of forest areas of Rewa district like Jawa, Dabhoura and Tyonthar, they were facing dacoit problem also. 53.5\% subcentres were covering 5-10 villages and $20.2 \%$ were covering even more than 10 villages. DLHS-3 reports that only $57 \%$ villages in MP are in the $3 \mathrm{Km}$ range of subcentres. Distance affects the quality of services. Only $57.1 \%$ of studied subcentres had subcentre buildings which is near survey findings in DLHS-3 i.e.55.6\% [3].

All of our studied ANMs admitted that vaccines are regularly available at their centers on time. Emphasis should be placed not only on BCG, DPT, OPV vaccination but also on Measles vaccination. Vaccination should be offered to any child who comes for curative visits after 9 months of age and laying emphasis that minor ARI, Diarrhoeal illness are no contraindication for vaccination [7].
All ANMs admitted that they get medicines for minor illnesses like Cotrimoxazole, Mebendazole, Paracetamole ,tab.Iron Folic acid, ORS etc. but they were unaware of identifying danger signs or illnesses like pneumonia, anemia, malnutrition in children. Government health worker's skills were not satisfactory for assessment of illness severity among young infants. During training importance of these signs needs to be emphasized [8].

31.5\% PHCs were situated more than $50 \mathrm{~km}$ from Rewa headquarter. Some of them like Raipur Sonori and Padri were even 90-100 kms from Rewa.There were 31.2\% primary health centres of study cohort, where no doctor was available. Though $43.7 \%$ PHCs were having one doctor and rest $25 \%$ having two doctors but those doctors were also involved to manage PHCs without doctors. In Madhya Pradesh 280 doctors are lacking against recommended posts at PHCs but in states like Kerala doctors are in excess [9].

Most PHCs were not having staff nurses. According to NFHS-3 there is shortfall of 2138 staff nurses in Madhya Pradesh. On the other hand in Kerala they are in excess [9]. 56.2\% primary health centres were not conducting deliveries due to lack of staff and other facilities. Only two PHC staff was trained in newborn resuscitation but resuscitation kits were not available in any PHC.

Medicines for minor illnesses were usually available in most PHCs but availability of oxygen cylinder was poor. At $88 \%$ PHCs critical newborn patients were being referred to higher centres by private hired vehicles though at three centres Janani express was 
being used but its poor availability at distant centres reduces its utility in remote areas. Properly managed neonatal transport is necessary. Proper support of newborn during transport either by mother or by health worker has been found to decrease the incidence of various complications. A suitable vehicle which is completely meant for the sick newborn, in which its care would not be jeopardized and frequent monitoring can be done, is to be adopted [10].

$80 \%$ CHCs were established covering a huge population i.e. more than 2 lacs in spite of a difficult geographical situations in Rewa district. Though the recommended population norms for $\mathrm{CHC}$ establishment are $1,20,000$ for plain area 80,000 for hilly/tribal/difficult area [6]

CHCs though are designated as BEmONC and CEmONC still lacking specialist doctors. Only 3 pediatricians were there in different CHCs. There was no anesthetist in any $\mathrm{CHC}$ therefore difficult deliveries have to be referred to Medical College Hospital Rewa for operative procedures in spite of having gynecologists at two CHCs. In whole Madhya Pradesh only 67 pediatricians are working at $\mathrm{CHCs}$ against 160 sanctioned posts, though 333 pediatricians are required [9]. Even in developed states like Kerala there is shortfall of 94 specialists at $\mathrm{CHCs}$ but none for pediatricians [9].

OPD of $90 \%$ CHCs hosts a huge crowd daily. Most of the OPD patients are children. Though 60\% CHCs are providing indoor facility to their pediatric patients but lack of 24 hours specialized care, they are mostly referred to GMH Rewa if needs long stay at hospital. Only three CHCs i.e. Hanumana, Sirmour and Jawa are using their neonatal care equipments for providing essential newborn care. Equipments available at other $\mathrm{CHCs}$ either not working or due to lack of experienced staff, are not used.

Essential newborn care trainings were highly demanded by doctors/staff nurses. Due to increased number of hospital deliveries, they are facing day to day problems regarding poor outcome of normal vaginal deliveries. It is suggested that there is association between newborn care practices and antenatal care, counseling and skilled delivery. Evidence based newborn care practices can be promoted through improved coverage with existing health services [11].

\section{Conclusion}

Basic infrastructure and skilled health care staff is lacking in Rewa district to cope up with requirements of a huge population scattered in difficult terrain with improper transportation facilities. Improvement in infrastructure and specialist facilities in newborn and child health may enhance neonatal and child health care services and thus will lead to improved health indicators in Rewa district.

\section{Funding: None \\ Conflict of Interest: None}

\section{References}

1. Geography of Rewa district. Available from: http://rewa.nic.in/Geography.htm accessed on 18/08/2015.

2.National family health survey (nfhs-3)India (2005-06) Madhya Pradesh available from: http://www.rchiips.org/nfhs/pdf/Madhya\%20Pradesh.pd f accessed August $19^{\text {th }} 2015$.

3.Status of child mortality in Madhya Pradesh (2011). Available from: http://www.mediaforrights.org/custom/docs/infopack/en /imr\%20of\%20mp.pdf accessed August 19 2015.

4. District level household and facility survey: Fact sheet of Madhya Pradesh (2007-08).Available from: http://nrhm.gov.in/nrhm-in-state/state-wise-

information/madhya-pradesh.html\#health_profile_mp accessed August $19^{\text {th }} 2015$.

5. UNDP. Human Development Report 2003, Millennium Development Goals: A compact among nations to end human poverty, oxford university press.

6. Park K. In: Health care of the community. Textbook of preventive and social medicine. $22^{\text {nd }} e d$. Jabalpur, India: Bhanot publishers;2013.P.843-47.

7. Deshpande $\mathrm{R}$, Nimbalkar S, Banker $\mathrm{N}$ et al. Prevalence of missed opportunities for Measles immunization in rural areas of Gujarat. Indian $J$. Pediatr. 2001; 68(7): 609-612.

8. Bandyopadhyay S, Kumar R, Singhi S et al. Are primary health workers skilled enough to assess the severity of illness among young infants? Indian Pediatr. 2003 Aug;40(8):713-18.

9. Bulletin or Rural Health statistics in India (updated up to March 2012). Available from: 
http://mohfw.nic.in/WriteReadData/1892s/492794502R

HS\%202012.pdf accessed August $24^{\text {th }} 2015$.

10. Mukesh C.V. Different means of neonatal transport, pattern of various factors influencing it and its related complications [M.D. thesis].India:A.P.S. University Rewa; 2008.

11. Baqui A.H. Williams E K, Darmstadt G L et al. Newborn care in rural Uttar Pradesh. Indian J Pediatr. 2007; 74(3): 241-247.

\section{How to cite this article?}

Gupta R, Gupta J. Child health Care delivery system in Rewa District: A critical analysis . Pediatr Rev: Int J Pediatr Res 2015;2(3):10-14. doi: 10.17511/ijpr.2015.i03.02 